\title{
Impact of tropospheric nitrogen dioxide on the regional radiation budget
}

\author{
A. P. Vasilkov ${ }^{1}$, J. Joiner ${ }^{2}$, L. Oreopoulos ${ }^{2}$, J. F. Gleason ${ }^{2}$, P. Veefkind ${ }^{3}$, E. Bucsela ${ }^{4}$, E. A. Celarier ${ }^{5}$, R. J. D. Spurr ${ }^{6}$, \\ and S. Platnick ${ }^{2}$ \\ ${ }^{1}$ Science Systems and Applications Inc., Lanham, MD, USA \\ ${ }^{2}$ Goddard Space Flight Center, Greenbelt, MD, USA \\ ${ }^{3}$ Royal Netherlands Meteorological Institute (KNMI), de Bilt, The Netherlands \\ ${ }^{4}$ SRI International, Menlo Park, CA, USA \\ ${ }^{5}$ University of Maryland, Baltimore County, USA \\ ${ }^{6}$ RT Solutions, Cambridge, MA, USA
}

Received: 11 March 2009 - Published in Atmos. Chem. Phys. Discuss.: 3 June 2009

Revised: 21 August 2009 - Accepted: 24 August 2009 - Published: 4 September 2009

\begin{abstract}
Following the launch of several satellite ultraviolet and visible spectrometers including the Ozone Monitoring Instrument (OMI), much has been learned about the global distribution of nitrogen dioxide $\left(\mathrm{NO}_{2}\right) . \mathrm{NO}_{2}$, which is mostly anthropogenic in origin, absorbs solar radiation at ultraviolet and visible wavelengths. We parameterized $\mathrm{NO}_{2}$ absorption for fast radiative transfer calculations. Using this parameterization with cloud, surface, and $\mathrm{NO}_{2}$ information from different sensors in the NASA A-train constellation of satellites and $\mathrm{NO}_{2}$ profiles from the Global Modeling Initiative (GMI), we compute the global distribution of net atmospheric heating (NAH) due to tropospheric $\mathrm{NO}_{2}$ for January and July 2005. The globally-averaged NAH values due to tropospheric $\mathrm{NO}_{2}$ are very low: they are about $0.05 \mathrm{~W} / \mathrm{m}^{2}$. While the impact of $\mathrm{NO}_{2}$ on the global radiative forcing is small, locally it can produce instantaneous net atmospheric heating of $2-4 \mathrm{~W} / \mathrm{m}^{2}$ in heavily polluted areas. We assess the impact of clouds and find that they reduce the globallyaveraged NAH values by $5-6 \%$ only. However, because most of $\mathrm{NO}_{2}$ is contained in the boundary layer in polluted regions, the cloud shielding effect can significantly reduce the net atmospheric heating due to tropospheric $\mathrm{NO}_{2}$ (up to $50 \%$ ). We examine the effect of diurnal variations in $\mathrm{NO}_{2}$ emissions and chemistry on net atmospheric heating and find only a small impact of these on the daily-averaged heating (11-14\% at the most). We also examine the sensitivity of $\mathrm{NO}_{2}$ absorption to various geophysical conditions. Effects of the vertical distri-
\end{abstract}

Correspondence to: A. P. Vasilkov (alexander_vassilkov@ssaihq.com) butions of cloud optical depth and $\mathrm{NO}_{2}$ on net atmospheric heating and downwelling radiance are simulated in detail for various scenarios including vertically-inhomogeneous convective clouds observed by CloudSat. The maximum effect of $\mathrm{NO}_{2}$ on downwelling radiance occurs when the $\mathrm{NO}_{2}$ is located in the middle part of the cloud where the optical extinction peaks.

\section{Introduction}

The absorption of incoming solar and outgoing terrestrial radiation by trace gases is one of the key factors in the Earth's radiative budget and plays a leading role in climate change (Hansen et al., 2007). Carbon dioxide $\left(\mathrm{CO}_{2}\right)$ is the largest anthropogenic climate forcing gas, but other trace gases are also important including methane $\left(\mathrm{CH}_{4}\right)$, tropospheric ozone $\left(\mathrm{O}_{3}\right)$, nitrous oxide $\left(\mathrm{N}_{2} \mathrm{O}\right)$, and halocarbons such as chlorofluourcarbons (CFCs) (Forster et al., 2007). Little attention has been paid to nitrogen dioxide $\left(\mathrm{NO}_{2}\right)$, because its effect on the global radiative budget, particularly the radiative forcing, is small. However, on a local scale, enhanced $\mathrm{NO}_{2}$ in polluted areas can change the partitioning of absorbed solar radiation between the atmosphere and surface; it produces atmospheric heating in the troposphere and contributes to dimming (reduction of solar radiation) at the surface.

Solomon et al. (1999) showed that $\mathrm{NO}_{2}$ can produce significant absorption of solar radiation locally under some conditions. During several days of ground-based observations in a moderately polluted area (Boulder, Colorado, USA), the

Published by Copernicus Publications on behalf of the European Geosciences Union. 
peak absorption of downwelling radiation by $\mathrm{NO}_{2}$ was $5-$ $12 \%$. The estimated peak net heating was in the range of $5-30 \mathrm{~W} / \mathrm{m}^{2}$. The high peak values appeared to be influenced by lightning-generated $\mathrm{NO}_{\mathrm{x}}$ associated with thunderstorms.

$\mathrm{NO}_{2}$ trends spanning a decade have been derived with data from the Global Ozone Monitoring Experiment (GOME), the Scanning Imaging Absorption Chartography (SCIAMACHY), and the Ozone Monitoring Instrument (OMI) (e.g., Richter et al., 2005; van der A et al., 2006, 2008). In some areas, $\mathrm{NO}_{2}$ has increased significantly. For instance in the Shanghai region, tropospheric $\mathrm{NO}_{2}$ increased $\sim 29 \%$ /year since 1996. In other areas, $\mathrm{NO}_{2}$ has been decreasing. Reductions of up to $7 \%$ per year have been observed in Europe and parts of the eastern United States.

In this paper, we compute the global distribution of the net atmospheric heating (NAH) due to tropospheric $\mathrm{NO}_{2}$ with an emphasis on polluted areas. We also examine the sensitivity of the $\mathrm{NO}_{2} \mathrm{NAH}$ to various geophysical parameters including the vertical cloud distribution. Here, we use several data sets from the NASA A-train constellation of afternoon satellites flying within fifteen minutes of each other near 13:30 local solar time. These include cloud and surface properties from the NASA Aqua Moderate Resolution Imaging Spectroradiometer (MODIS) on the Auqua platform and tropospheric $\mathrm{NO}_{2}$ and cloud pressure from OMI, which flies on the NASA Aura satellite.

The organization of the paper is as follows: in Sect. 2, we develop a parameterization of $\mathrm{NO}_{2}$ absorption that is used in a radiative transfer scheme to compute $\mathrm{NO}_{2} \mathrm{NAH}$. In Sect. 3, we show how the vertical profiles of $\mathrm{NO}_{2}$ and cloud optical depth affect NAH and downwelling surface radiances for clear-sky and cloudy conditions. In Sect. 4, we present computed global and regional distributions of the tropospheric $\mathrm{NO}_{2} \mathrm{NAH}$ based on $\mathrm{NO}_{2}$ amounts derived from OMI observations and cloud data taken from MODIS and OMI retrievals. Conclusions are given in Sect. 5.

\section{Parameterization of $\mathrm{NO}_{2}$ absorption}

$\mathrm{NO}_{2}$ absorbs solar radiation throughout the spectral range $300-650 \mathrm{~nm}$ with a peak near $400 \mathrm{~nm}$. The temperature dependence of the $\mathrm{NO}_{2}$ absorption is weak, so we neglect it and use the cross section at $294 \mathrm{~K}$ from Vandaele et al. (1998). In this work, we neglect a small portion $(<1 \%)$ of absorbed energy that goes to $\mathrm{NO}_{2}$ fluorescence (Thornton et al., 2000).

Figure 1 shows the optical thickness, $\tau$, for a vertical path through an $\mathrm{NO}_{2}$ column amount of 0.5 Dobson Units (DU, $1 \mathrm{DU}=1.343 \times 10^{16} \mathrm{~mol} / \mathrm{cm}^{2}$ ), that is typical of heavily polluted areas (e.g., Cede et al., 2005) and the approximate spectral absorption of solar irradiance $A=F \tau \approx F(1-\exp (-\tau))$, where $F$ is the extraterrestrial solar irradiance. The low values of optical thickness even for high $\mathrm{NO}_{2}$ amounts indicate that $\mathrm{NO}_{2}$ is a relatively weak absorber. According to the data

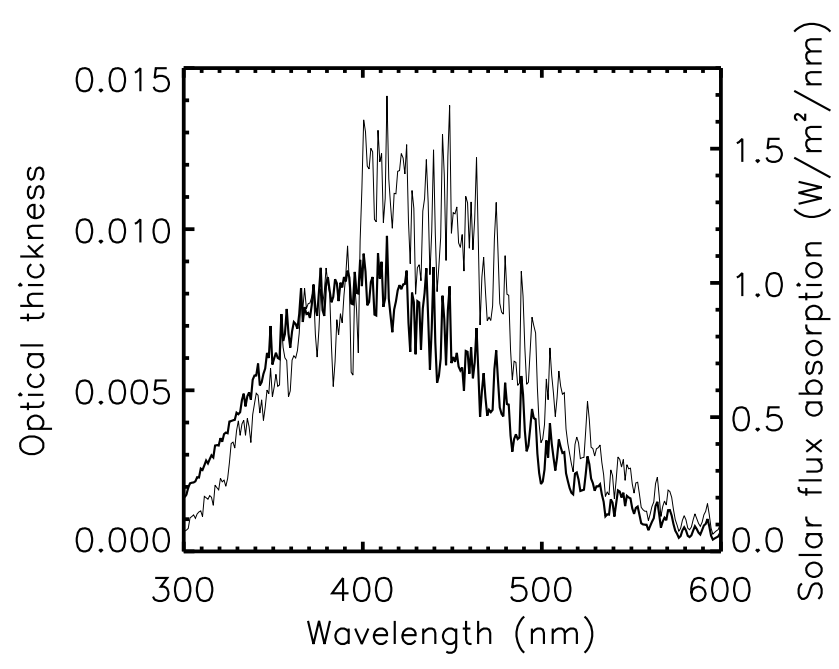

Fig. 1. Thick line: spectral optical thickness, $\tau$ (left scale) for $0.5 \mathrm{DU}$ of $\mathrm{NO}_{2}$. Thin line: corresponding approximate absorption, $A$, of solar irradiance by $\mathrm{NO}_{2}$ (right scale).

Table 1. Fractional solar flux $\left(F / F_{0}\right)$ and effective $\mathrm{NO}_{2}$ absorption coefficients $\left(a_{\mathrm{eff}}\right)$.

\begin{tabular}{lrr}
\hline Spectral band $(\mathrm{nm})$ & $F / F_{0}$ & $a_{\text {eff }}\left(\mathrm{cm}^{2}\right)$ \\
\hline $320-400$ & 0.0591 & $4.872 \times 10^{-19}$ \\
$400-700$ & 0.3908 & $1.992 \times 10^{-19}$ \\
\hline
\end{tabular}

in Fig. 1, most solar absorption takes place in the spectral range of $350-500 \mathrm{~nm}$.

To reduce the computational burden for heating calculations, we parametrize the spectral $\mathrm{NO}_{2}$ absorption coefficients following Chou and Lee (1996). The transmission function averaged over a spectral band is first calculated from

$T(w / \mu)=\frac{\int_{\lambda_{1}}^{\lambda_{2}} F(\lambda) \exp [-a(\lambda) w / \mu] d \lambda}{\int_{\lambda_{1}}^{\lambda_{2}} F(\lambda) d \lambda}$,

where $w$ is the $\mathrm{NO}_{2}$ column amount, $F$ is the extraterrestrial solar flux, $a$ is the $\mathrm{NO}_{2}$ absorption coefficient, and $\mu$ is the cosine of the solar zenith angle (SZA). An effective absorption coefficient, $a_{\text {eff }}$, for a given spectral band is then derived by inverting the transmittance function:

$a_{\mathrm{eff}}=\ln [T(w / \mu)] \mu / w$.

Variations of $a_{\mathrm{eff}}$ with $w / \mu$ are relatively small and do not exceed 5\% for realistic values of $w / \mu$. Table 1 gives the mean values of $a_{\text {eff }}$ for the two spectral bands in the Chou and Suarez (2002) algorithm where $\mathrm{NO}_{2}$ absorption is significant.

To assess the overall efficiency of the parameterization, we compute $\mathrm{NO}_{2} \mathrm{NAH}$ using the high spectral resolution 


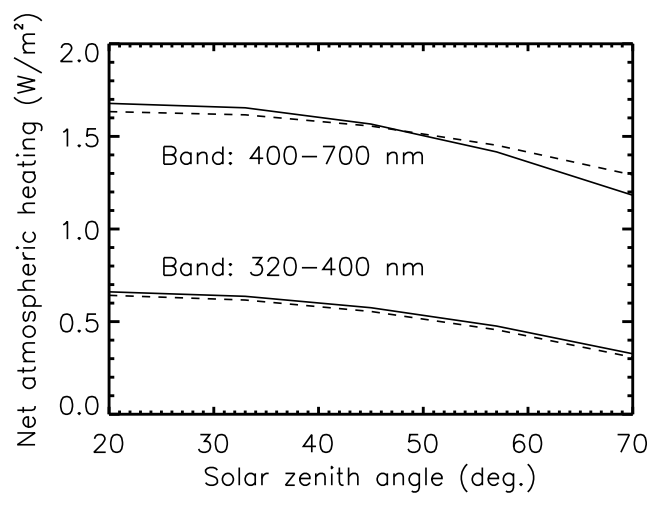

Fig. 2. $\mathrm{NO}_{2}$ net atmospheric heating computed with the high spectral resolution (solid line) and the effective (dashed line) absorption coefficient.

and effective absorption coefficients in clear skies for different SZAs. The calculations are performed with the Linearized Discrete-Ordinate Radiative Transfer-Rotational Raman Scattering (LIDORT-RRS) code that does not account for polarization (Spurr et al., 2008). In general, the NAH is defined as

$$
Q=\left(F_{d}-F_{u}\right)_{\mathrm{TOA}}-\left(F_{d}-F_{u}\right)_{\text {surface }},
$$

where $F_{d}$ and $F_{u}$ are the downward and upward irradiances, respectively, and the subscripts TOA and surface refer to the top-of-atmosphere and ground, respectively. All NAHs reported here are those due to tropospheric $\mathrm{NO}_{2}$, i.e., $Q=$ $Q_{\text {trop } \mathrm{NO}_{2}}-Q_{\text {no tropNO }}$.

Figure 2 shows that the difference between the NAH computed at high spectral resolution and with the parameterization does not exceed $5 \%$ for $\mathrm{SZA}<60^{\circ}$ in either spectral band. To compute the NAH in Fig. 2, we use a total $\mathrm{NO}_{2}$ column amount of $0.5 \mathrm{DU}$ distributed uniformly in the lowest $\mathrm{km}$ of the atmosphere. The surface albedo is set to 0.05 .

It should be noted that no other atmospheric absorbers are included in this computation and computations carried out for sensitivity studies described in Sect. 3. An important absorber in the spectral range of $320-700 \mathrm{~nm}$ is ozone. Ozone absorption can affect $\mathrm{NO}_{2} \mathrm{NAH}$ because ozone absoption in the stratosphere reduces downwelling flux thus decreasing $\mathrm{NO}_{2}$ heating in the planetary boundary layer where most $\mathrm{NO}_{2}$ is confined in polluted land regions. However, this effect is small. We performed computations of NAH for three cases: ozone and $\mathrm{NO}_{2} Q_{\mathrm{O}}+\mathrm{NO}_{2}$, ozone alone, $Q_{\mathrm{O}_{3}}$, and $\mathrm{NO}_{2}$ alone, $Q_{\mathrm{NO}_{2}}$, in the spectral range of $320-400 \mathrm{~nm}$. The difference $Q_{\mathrm{O}_{3}}+\mathrm{NO}_{2}-Q_{\mathrm{O}_{3}}$, that characterizes $\mathrm{NO}_{2}$ heating in the presence of ozone absorption, appears to be less than $Q_{\mathrm{NO}_{2}}$ just by $1.7 \%$ (at $\mathrm{SZA}=45^{\circ}$ ). In computations of global and regional NAH described in Sect. 4, we accounted for ozone absorption and calculated the $\mathrm{NO}_{2} \mathrm{NAH}$ as the difference $Q_{\mathrm{O}_{3}+\mathrm{NO}_{2}}-Q_{\mathrm{O}_{3}}$.

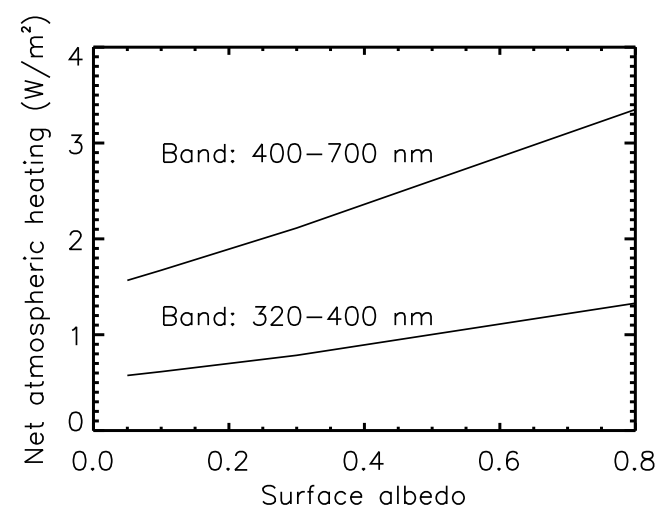

Fig. 3. $\mathrm{NO}_{2}$ net atmospheric heating dependence on surface albedo.

\section{Sensitivity studies}

To better understand the global calculations of $\mathrm{NO}_{2} \mathrm{NAH}$ that are shown in the next section, we first perform a series of sensitivity tests. These tests are conducted at a SZA of $45^{\circ}$ with the high spectral resolution absorption coefficients.

Our calculations show that the dependence of the NAH on the vertical distribution of tropospheric $\mathrm{NO}_{2}$ in clear skies is relatively small. For instance, when the top of a $0.5 \mathrm{DU}$ $1 \mathrm{~km}$ thick layer of $\mathrm{NO}_{2}$ increases from 1 to $3 \mathrm{~km}$, the $\mathrm{NAH}$ increases $\sim 8 \%$ in the $400-700 \mathrm{~nm}$ band and $\sim 15 \%$ in 320 $400 \mathrm{~nm}$ band. The total increase of the NAH in the two bands is $\sim 10 \%$.

Figure 3 shows the dependence of the NAH on surface albedo for clear skies with $0.5 \mathrm{DU}$ of $\mathrm{NO}_{2}$ placed in the lowest $\mathrm{km}$. The significant increase of NAH with surface albedo is a result of enhanced photon path lengths through the $\mathrm{NO}_{2}$ layer at higher albedos owing to an increase in photons reflected from the surface.

We next investigate the impact of clouds on the tropospheric $\mathrm{NO}_{2} \mathrm{NAH}$. We take the phase function to have the Henyey-Greenstein form with an asymmetry parameter of 0.85 . This corresponds to water clouds with equivalent droplet radius of $6 \mu \mathrm{m}$ (Hu and Stamnes, 1993).

The impact of clouds on the NAH is significant and depends on both the vertical cloud structure and the placement of $\mathrm{NO}_{2}$ with respect to the cloud. For $\mathrm{NO}_{2}$ above a cloud layer, the cloud increases the tropospheric (or stratospheric) $\mathrm{NO}_{2} \mathrm{NAH}$ similar to the effect of a higher surface albedo.

We next consider an $\mathrm{NO}_{2}$ layer that lies entirely below a cloud. Here, we use a vertically uniform cloud with a geometrical thickness of $1 \mathrm{~km}$. The cloud bottom was placed just above the $\mathrm{NO}_{2}$ layer located in the lowest $\mathrm{km}$. In this situation, the cloud reduces the tropospheric $\mathrm{NO}_{2} \mathrm{NAH}$. The NAH dependence on cloud optical depth, $\tau$, is shown in Fig. 4.

In this work, we define the NAH for a partly cloudy scene as $Q=Q_{\text {clr }}(1-f)+Q_{\text {cld }} f$, where $f$ is the geometrical cloud fraction, and $Q_{\text {clr }}$ and $Q_{\text {cld }}$ are the NAH for clear and 


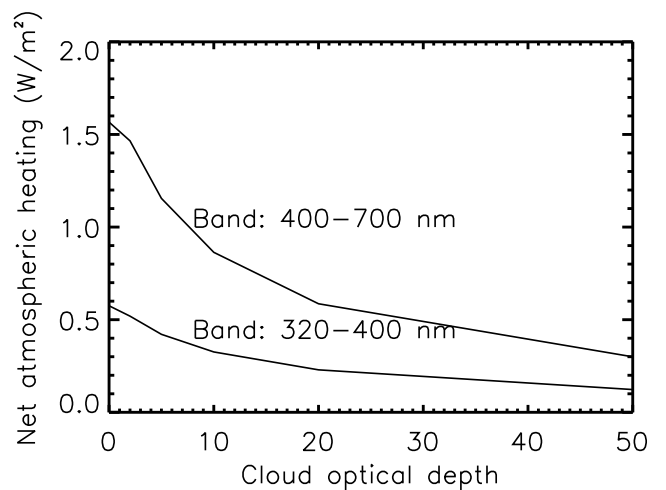

Fig. 4. $\mathrm{NO}_{2}$ net atmospheric heating dependence on cloud optical depth, $\tau$, when the $\mathrm{NO}_{2}$ layer is below the cloud.

overcast skies, respectively. This definition follows the socalled independent pixel approximation and assumes there is no radiative interaction between clear and cloudy pixels. For the above scenario with the cloud placed just above the $\mathrm{NO}_{2}$ layer (in the lowest $\mathrm{km}$ ), $\mathrm{NAH}$ decreases linearly with increasing cloud fraction. The slope of the NAH dependence on cloud fraction is dependent on $\tau$.

We next perform radiative transfer simulations in realistic vertically extended clouds to study the effect of the vertical distribution of $\mathrm{NO}_{2}$ within a cloud. We use the two cloud optical extinction profiles shown in the left panel of Fig. 5. They are derived from CloudSat radar reflectivities (Stephens et al., 2002) and MODIS TOA reflectances. We use the CloudSat standard product 2B-TAU that provides cloud optical depth by layer (Stephens et al., 2008). Vasilkov et al. (2008) and Ziemke et al. (2009) used these profiles to examine ozone absorption and rotational-Raman scattering within clouds and showed that they are typical for tropical deep convection. The total cloud optical depths are 32 and 66 for profiles 1 and 2, respectively. The cloud tops as detected by both MODIS and CloudSat are within 150-250 hPa for both profiles. The profiles show the clouds to be optically thin near the tops.

The middle panel of Fig. 5 shows the NAH (300-700 nm) as a function of $\mathrm{NO}_{2}$ layer midpoint for the two CloudSat profiles. The $\mathrm{NO}_{2}$ layer is $0.5 \mathrm{DU}$ distributed uniformly within $1 \mathrm{~km}$. Also shown is the NAH computed for a vertically uniform distribution of $\mathrm{NO}_{2}$ throughout the clouds (0.5 DU). The NAH is minimal when the $\mathrm{NO}_{2}$ is located in the lower-most portions of the clouds. For profile 1, the NAH increases rapidly for $\mathrm{NO}_{2}$ layer heights between $\sim 3$ and $7 \mathrm{~km}$ as the in-cloud multiple scattering increases. The NAH then decreases with $\mathrm{NO}_{2}$ layer height for layers near the cloud top. The NAH for profile 2 exhibits a plateau when the $\mathrm{NO}_{2}$ is located in between the two distinct cloud layers. The $\mathrm{NO}_{2}$ layer heights at which the NAH are equal to values for the vertically uniform $\mathrm{NO}_{2}$ distribution throughout the clouds differ noticeably for two cloud profiles.
To simulate the Solomon et al. (1999) measurements of downwelling zenith surface radiance, we also calculate the fractional change of surface zenith radiances due to tropospheric $\mathrm{NO}_{2}: I / I_{0}-1$, where $I$ and $I_{0}$ are the zenith radiances at $400 \mathrm{~nm}$ calculated with and without $\mathrm{NO}_{2}$, respectively. Solomon et al. (1999) performed calculations assuming a vertically uniform cloud and suggested that the cloud effect on $\mathrm{NO}_{2}$ absorption would be greatest if the $\mathrm{NO}_{2}$ is placed near the cloud top.

The right panel of Fig. 5 shows the changes of the zenith radiance as a function of the $\mathrm{NO}_{2}$ layer height for the two CloudSat profiles along with that computed for a vertically uniform distribution of $\mathrm{NO}_{2}$ throughout the clouds. It is interesting to note that the maximum effect of $\mathrm{NO}_{2}$ absorption on the zenith radiance occurs when the $\mathrm{NO}_{2}$ is located near the peak of the cloud extinction. The maximum photon path enhancement takes place in the most scattering portion of clouds, and that is where the $\mathrm{NO}_{2}$ absorption effect on the downwelling radiance is also at a maximum.

\section{Global $\mathrm{NO}_{2}$ net atmospheric heating calculations}

In this section, we perform global radiative transfer (RT) calculations with a stand-alone version of the algorithm developed by Chou and Suarez (2002) (henceforth referred to as CS). The algorithm has been used in various atmospheric models in the NASA Goddard Laboratory for Atmospheres, We first provide brief descriptions of the CS algorithm and input data sets.

\subsection{Chou-Suarez (CS) radiative transfer algorithm}

In the CS algorithm, the short-wave spectrum is divided into 8 bands in the ultraviolet (UV) and photo-synthetically active (PAR) regions with a single ozone absorption coefficient and Rayleigh scattering coefficient in each band. $\mathrm{NO}_{2}$ absorption is similarly accounted for in two bands: $320-400$ and 400 $700 \mathrm{~nm}$ using the effective absorption coefficients listed in Table 1.

Reflection and transmission of cloud layers are calculated using the $\delta$-Eddington approximation, and fluxes are computed with a two-stream model. Data provided by Yang et al. (2000) for ice clouds and Tsay et al. (1989) for water clouds are used to derive an effective band-mean single scattering albedo, extinction coefficient, and asymmetry factor. Aerosol is not included in our computations. Roughly, aerosol acts like a cloud of low optical depth and the OMI cloud algorithm treats it as such.

\subsection{Input data sets}

\subsection{1 $\mathrm{OMI} \mathrm{NO}_{2}$ retrievals}

Here we briefly describe the standard $\mathrm{OMI} \mathrm{NO}_{2}$ algorithm and retrievals. Additional details can be found in Bucsela et 

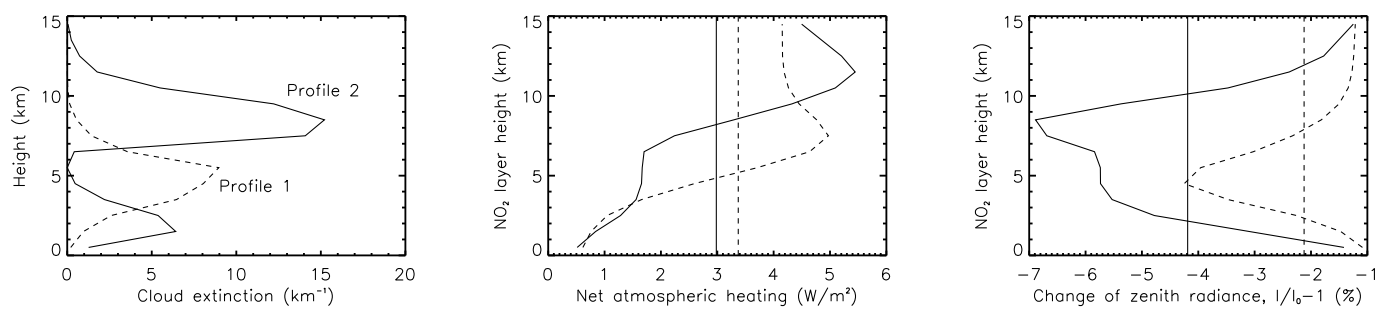

Fig. 5. Left: cloudSat/MODIS cloud extinction profiles used in radiative transfer simulations; middle: net heating dependence on the $1 \mathrm{~km}$ $\mathrm{NO}_{2}$ layer midpoint. Dashed(solid) lines are for CloudSat profiles 1(2); vertical lines are for uniform distributions of $\mathrm{NO}_{2}$ inside the clouds; right: as in middle but for zenith radiances.

al. (2006, 2008) and Celarier et al. (2008). OMI provides daily global coverage with a swath width of $2600 \mathrm{~km}$ (Levelt et al., 2006). The $\mathrm{NO}_{2}$ level 2 retrievals are reported at the nominal OMI spatial resolution ( $13 \mathrm{~km} \times 24 \mathrm{~km}$ at nadir).

$\mathrm{NO}_{2}$ total column amounts are retrieved with a differential optical absorption spectroscopy (DOAS) technique using OMI TOA reflectance spectra. First, $\mathrm{NO}_{2}$ slant column amounts are estimated by spectral fitting within the wavelength region 415-465 nm (Bucsela et al., 2006; Celarier et al., 2008). This spectral range falls within OMI's visible detector that has a spectral resolution of about $0.6 \mathrm{~nm}$. Initial vertical column amounts are calculated using air mass factors (AMFs) for a stratospheric $\mathrm{NO}_{2}$ distribution, and are approximately geometric. Tropospheric AMFs are derived with gridded annual mean $\mathrm{NO}_{2}$ profiles from the GEOS-Chem model (Bey et al., 2001).

The $\mathrm{NO}_{2}$ stratosphere-troposphere separation is based on the fact that the stratospheric field has small gradients, particularly in the zonal direction. The slowly varying spatial component of the total $\mathrm{NO}_{2}$ column is identified as the stratospheric field and the rest is assigned to the troposphere. The initial tropospheric column amount is then multiplied by the ratio of the stratospheric-to-tropospheric AMFs.

The OMI NO 2 retrievals have been compared with in situ, ground-based, and aircraft measurements. Using in situ $\mathrm{NO}_{2}$ aircraft measurements, Bucsela et al. (2008) conclude that the OMI algorithm yields $\mathrm{NO}_{2}$ amounts lower than the in situ columns by a factor of 0.86 . Similarly, Celarier et al. (2008) report that the OMI tropospheric columns are underestimated by $15-30 \%$. Comparing the total $\mathrm{NO}_{2}$ amounts with those derived from ground-based direct-Sun Brewer measurements, Wenig et al. (2008) show that monthly averages of coinciding measurements correlate well, but OMI retrievals are about $25 \%$ lower than the Brewer data.

Because tropospheric $\mathrm{NO}_{2}$ has significant diurnal variations (Cede et al., 2005; Boersma et al., 2008), it is important to note that the OMI equator crossing time is 13:30 local time. The diurnal cycle of tropospheric $\mathrm{NO}_{2}$ is governed by emissions that are mostly due to human activities in urban regions and chemical loss that is strongest at midday. Therefore, the $\mathrm{NO}_{2}$ concentration exhibits a minimum near the afternoon OMI overpass time in urban regions (Boersma et al., 2008). As expected, OMI retrieves lower $\mathrm{NO}_{2}$ column amounts (20-30\%) over urban areas than SCIAMACHY, which has an equator crossing time of 10:00 (Boersma et al., 2008).

To compute global NAH, we use monthly mean values of the $\mathrm{OMI} \mathrm{NO}_{2}$ tropospheric column gridded to a resolution of $1^{\circ}$ latitude $\times 1^{\circ}$ longitude. We use the following filters to compute the gridbox means:

1. View zenith angles $<50^{\circ}$; this removes large-footprint pixels at the swath edge.

2. Radiative cloud fractions (percent of pixel radiance contributed by cloudy portion of the scene) $<30 \%$. This removes pixels where significant amounts of $\mathrm{NO}_{2}$ are shielded by clouds. The use of a threshold less than $30 \%$ gives similar results but worse cover.

3. South Atlantic anomaly (SAA) flag bit set to zero or SAA flag $>0$ and the fitting $\chi^{2}<1500$.

4. Processing quality flag bits 0 and 1 equal to zero (for information about the flags, see http://toms.gsfc.nasa.gov/ omi/no2/OMNO2_readme.pdf).

Figure 6 shows the well-known seasonal variability in tropospheric $\mathrm{NO}_{2}$ column amounts as observed by OMI. In industrial regions, such as the eastern US, Europe, and Southeast Asia, the dominant source of $\mathrm{NO}_{2}$ emissions is anthropogenic. These areas have a column $\mathrm{NO}_{2}$ maximum in the winter due to the longer lifetime of $\mathrm{NO}_{\mathrm{x}}$ at that time of year (van der A et al., 2008). The effects of seasonal changes in biomass burning in Central Africa are also reflected in $\mathrm{NO}_{2}$ columns.

We use monthly-mean $\mathrm{NO}_{2}$ vertical distributions based on a simulation from the Global Modeling Initiative (GMI) chemistry-transport model (Duncan et al., 2007). We find that in polluted regions, most of the $\mathrm{NO}_{2}$ is contained within a layer about $200 \mathrm{hPa}$ thick above the surface. Rather than scaling the entire $\mathrm{NO}_{2}$ profile to give the OMI-derived $\mathrm{NO}_{2}$ column, we adjust the model $\mathrm{NO}_{2}$ profiles such that the total 

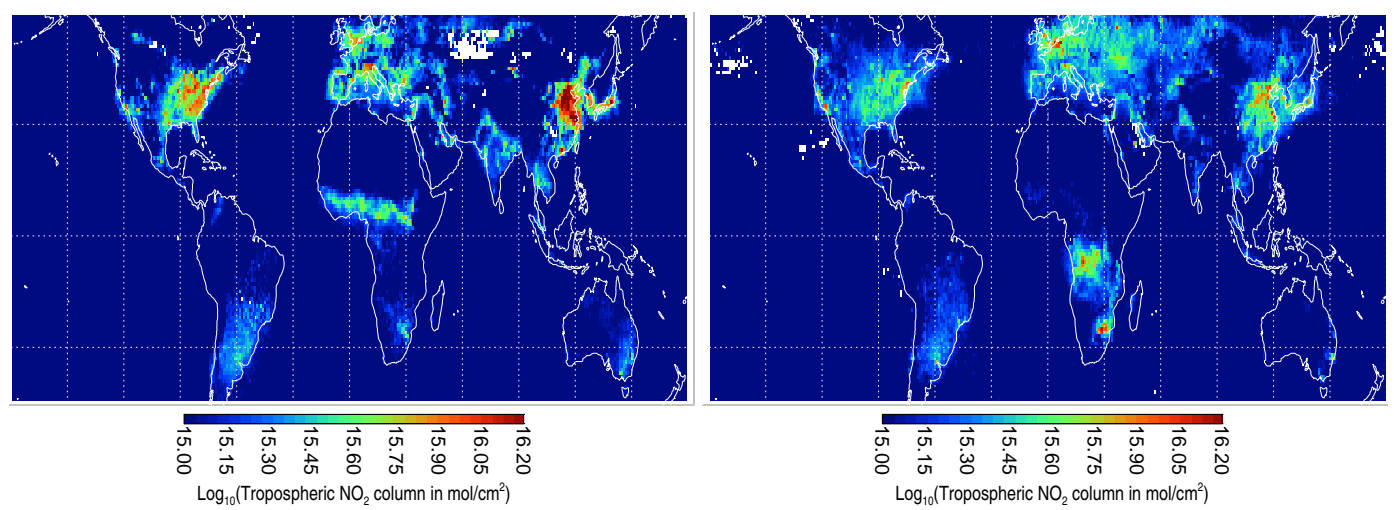

Fig. 6. Monthly-mean tropospheric $\mathrm{NO}_{2}$ column amounts for January (left) and July (right) 2005 from OMI. White areas correspond to pixels not meeting the cloud fraction criterion.

column amounts are equal to the gridded OMI monthly mean value by adding or subtracting an appropriate amount in a $200 \mathrm{hPa}$ thick layer just above surface. While there is little sensitivity to the $\mathrm{NO}_{2}$ profile shape in clear skies, the profile shape in cloudy conditions significantly affects the computed $\mathrm{NAH}$. The adjustment of $\mathrm{NO}_{2}$ profiles provides a more accurate estimate of the cloud effect.

It should be noted that we adjust the model $\mathrm{NO}_{2}$ profiles to the $\mathrm{NO}_{2}$ column data from OMI at 13:30 local time only. The $\mathrm{NO}_{2}$ diurnal cycle is neglected in our computations. We provide information about uncertainties in NAH, that are due to this simplifying assumption, in Sect. 4.3.3.

\subsubsection{Cloud data sets}

We use retrievals of cloud optical depth, effective radius, and phase from MODIS daily gridded $1^{\circ} \times 1^{\circ}$ level 3 (L3) data sets (Platnick et al., 2003) as described in detail by Joiner et al. (2009). The dataset includes separate statistical descriptions of parameters for ice and water clouds. We use the gridbox-mean effective radii and cloud optical depths for ice and water clouds, along with their associated cloud fractions. Joiner et al. (2009) showed that the use of daily gridbox-mean values, as opposed to the full gridbox statistical distributions that are provided in the MODIS data set, provides sufficiently good accuracy for RT calculations related to trace-gas absorption.

To compute NAH, we also need to specify the cloud extent. As in Joiner et al. (2009), we use optical centroid cloud pressures from the OMI rotational-Raman algorithm (Joiner et al., 2004; Joiner and Vasilkov, 2006). The optical centroid cloud pressures from this algorithm are similar to those derived from oxygen dimer and oxygen A-band absorption (Sneep et al., 2008) and are significantly different from the cloud-top pressure (Vasilkov et al., 2008). The optical centroid cloud pressure is more appropriate than cloud-top pressure for radiative calculations in the visible and ultraviolet because it accounts for photon penetration into the cloud (Ziemke et al., 2009).

We distribute the cloud optical depth uniformly in a $1 \mathrm{~km}$ layer centered at the OMI centroid cloud pressure. This provides a good first order approximation for cloud effects on trace-gas absorption at visible wavelengths when the absorber is well mixed (Ziemke et al., 2009). However, errors will occur in more complex situations such as when the absorber and cloud distributions are non-uniform as shown in Sect. 3. It is difficult to quantify the errors as the exact distributions in such situations are unknown.

\subsubsection{Surface albedo and other ancillary data sets}

As in Joiner et al. (2009), we specify the surface albedo separately for direct and diffuse fluxes using 16-day gridded albedos from the MODIS filled-land surface albedo product (MOD43B3) (Lucht et al., 2000). Over ocean, we use a model of the surface albedo from Jin et al. (2004) with the $2 \mathrm{~m}$ wind speed from the Goddard Earth Observing System 5 Data Assimilation System (GEOS-5 DAS) (Rienecker et al., 2007). Temperature, water vapor, and ozone profiles are also taken from the GEOS-5 DAS.

\subsection{Results}

\subsubsection{Diurnally-averaged net atmospheric heating}

Here, we compute monthly-mean $\mathrm{NO}_{2} \mathrm{NAH}$ by averaging values calculated every two hours. We fix the $\mathrm{NO}_{2}$ column amount at the OMI gridded monthly mean value, i.e., the value near 13:30 local time. This will produce systematic errors in the diurnally-averaged NAH that will depend upon the diurnal variations in $\mathrm{NO}_{2}$. The error magnitude is estimated in Sect. 4.3.3. Although we use monthly mean values of the tropospheric $\mathrm{NO}_{2}$ column for computing $\mathrm{NAH}$, we use daily cloud data from MODIS and OMI to properly account for the high variability of cloud optical thickness and pressure 

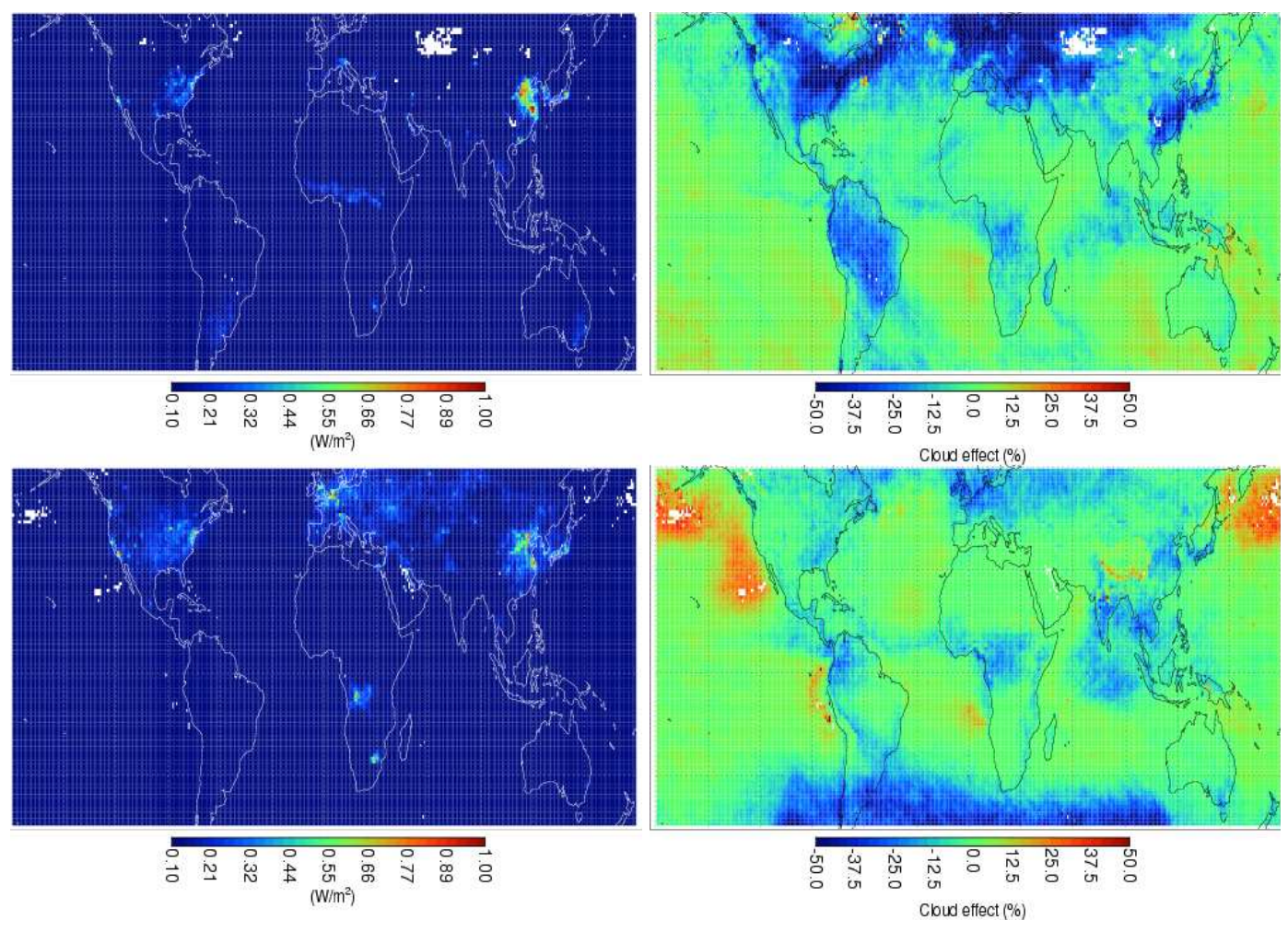

Fig. 7. Clear-sky daily-averaged NAH (left) and cloud effect in \% of clear-sky NAH (right) for January (top) and July (bottom) 2005.

and the non-linearity of these cloud parameters with respect to the $\mathrm{NO}_{2} \mathrm{NAH}$.

First of all, the globally-averaged NAH values are extremely low because of a very low spatial fraction of polluted areas and practically no tropospheric $\mathrm{NO}_{2}$ over the oceans. For instance, the globally-averaged NAH values are just $0.044 \mathrm{~W} / \mathrm{m}^{2}$ for July and $0.046 \mathrm{~W} / \mathrm{m}^{2}$ for January. The zonal mean of NAH for latitudes of $20^{\circ} \mathrm{N}$ to $60^{\circ} \mathrm{N}$ is approximately twice higher than the globally-averaged values.

Figure 7 shows the global distribution and seasonal variations in the NAH along with the cloud effect. The spatial distribution of the NAH primarily reflects the global distribution of $\mathrm{NO}_{2}$. However, the effect of SZA is also evident in the $\mathrm{NAH}$. For example, $\mathrm{NO}_{2}$ column amounts in European urban and industrial areas are somewhat higher than over Central Africa in January. The NAH over Europe, however, is lower than over Central Africa owing to the reduced amount of solar irradiance at high latitudes in January. The seasonal maximum of diurnally-averaged NAH for polluted extra-tropical regions is in summer owing to the greater amount of solar irradiance.

The cloud effect is defined as $Q$ allsky/ $Q$ clearsky- 1 . In polluted regions, large values of this parameter are mainly due to shielding of the planetary boundary layer (PBL) where most of the $\mathrm{NO}_{2}$ resides. This decreases atmospheric heating as shown in Fig. 7. The decrease (in terms of percent) is larger in winter than summer for most polluted areas. Clouds reduce the globally-averaged NAH values by $5-6 \%$ only. However, they can significantly reduce the regional $\mathrm{NAH}$ values in the polluted areas.

Over the ocean, $\mathrm{NO}_{2}$ is not so restricted to the PBL as it is in polluted land regions. Most of the tropospheric $\mathrm{NO}_{2}$ column over ocean results from pollution transport, $\mathrm{NO}_{2}$ brought down from the stratosphere through tropopause folds, and lightning. In this situation clouds can increase heating when $\mathrm{NO}_{2}$ is present above them as shown in Sect. 3 . However, the total amount of $\mathrm{NO}_{2}$ and associated heating over oceans is relatively small.

On the west coast US and in southern Europe during July, the net cloud effect is close to zero. In these areas there is a compensation of the cloud shielding and cloud enhancement effects.

\subsubsection{Instantaneous net atmospheric heating}

Figure 8 shows detailed maps of maximum daily (instantaneous) NAH over North America and Southeast Asia for January and July 2005. As noted above, the computed daily maxima assume a fixed $\mathrm{NO}_{2}$ column amount equal to the OMI-derived value. The winter instantaneous maximum NAH values are higher than summer values in many polluted areas in contrast with the diurnally-averaged NAH values. 

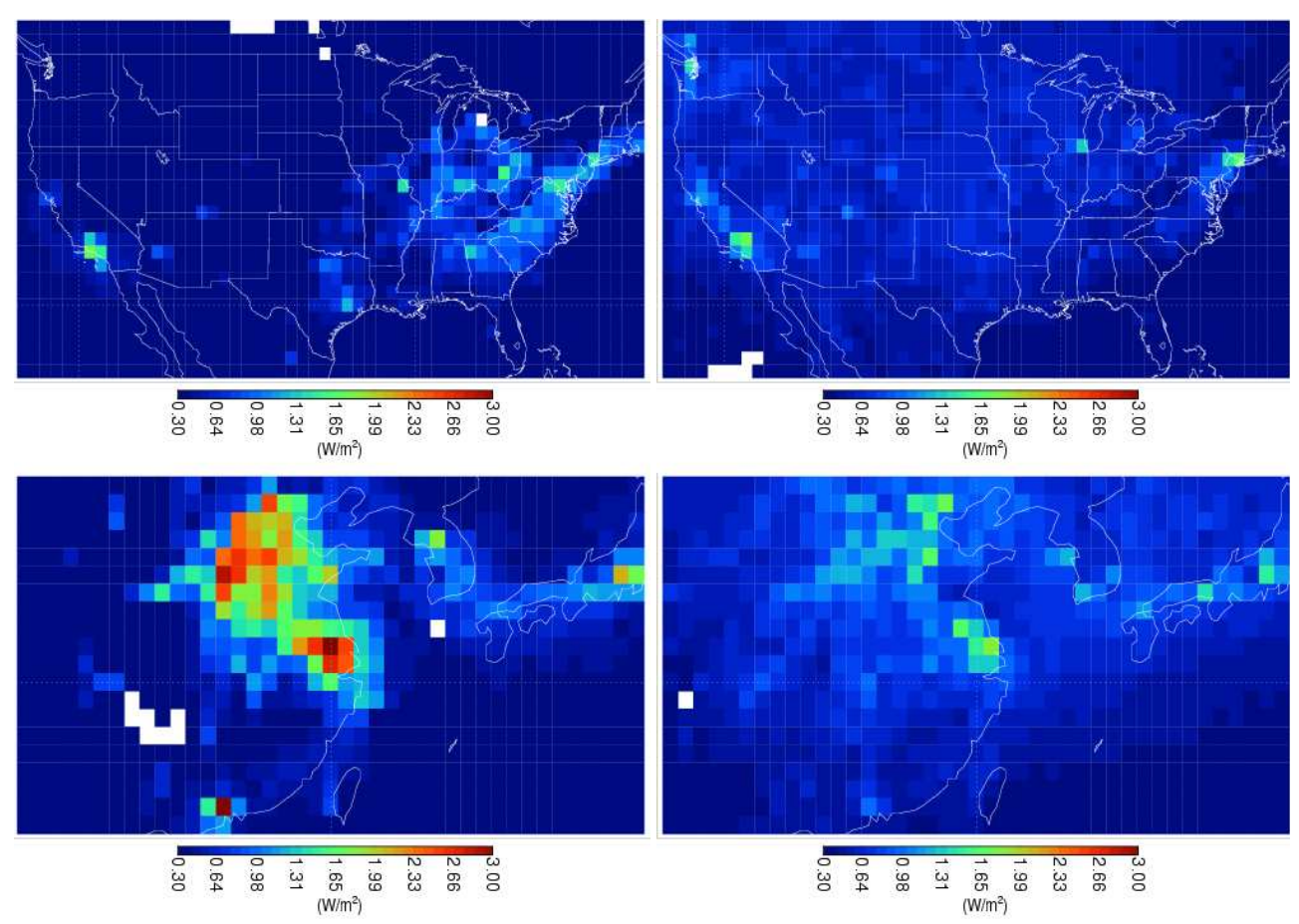

Fig. 8. Clear-sky daily maximum net atmospheric heating for January (left) and July (right) 2005 over the US (top) and Southeast Asia (bottom).

The instantaneous maximum NAH values are approximately a factor of 2 higher than the diurnally-averaged.

\subsubsection{Effect of time variations in sources and chemistry}

In the above calculations, we assumed a constant $\mathrm{NO}_{2}$ amount equal to the OMI-derived value near 13:30 local time. Here, we examine the effect of diurnal variations in $\mathrm{NO}_{2}$ on the calculated NAH. Figure 9 shows diurnal variations in the tropospheric $\mathrm{NO}_{2}$ column for two geographic regions in August 2006 as given by Boersma et al. (2008):

1. An urban area in the northeastern United States where $\mathrm{NO}_{2}$ amounts are dominated by fossil fuel burning

2. southern Africa, where $\mathrm{NO}_{2}$ is produced primarily from biomass burning

Three scenarios are considered:

1. constant $\mathrm{NO}_{2}$ amounts (equal to the $\mathrm{OMI}$ amount);

2. constant $\mathrm{NO}_{\mathrm{x}}$ emissions;

3. diurnally varying $\mathrm{NO}_{\mathrm{x}}$ emissions.

$\mathrm{NO}_{2}$ columns for the latter two cases were derived with the GEOS-Chem model (Boersma et al., 2008). To calculate SZAs needed for the NAH computations, we used $40^{\circ} \mathrm{N}$ and $20^{\circ} \mathrm{S}$ latitude for the US and African areas, respectively, for mid-August.
The instantaneous NAH values for these different scenarios are shown in Fig. 9 for cloud-free conditions. For the case of constant $\mathrm{NO}_{2}$, the variation of $\mathrm{NAH}$ is determined only by SZA changes. There are significant differences (up to $30 \%$ ) in the instantaneous NAH values calculated for the various scenarios and similar differences in the peak values for the urban case. However, daily-integrated and averaged NAHs differ less. Daily-averaged NAHs are lower for the constant $\mathrm{NO}_{2}$ amount as compared with the diurnally varying $\mathrm{NO}_{2}$ columns (11-14\% for the urban case and $1-6 \%$ for the biomass burning scenario). These differences are relatively small and represent an upper bound on the error in the computed diurnally-averaged NAH shown in Sect. 4.3.1. Note that the cloud effect reduces the error for an all-sky monthly mean.

\subsubsection{Effect of spatial resolution}

The effect of spatial resolution on the computed mean $\mathrm{NO}_{2}$ column is well known; averaging the data on a finer grid will produce larger peak values in polluted areas. The data may be averaged at a finer resolution than the actual pixel sizes. Because of the 32 day repeat cycle of the Aura spacecraft, the OMI pixel centers vary from day to day. Therefore, by spatial oversampling, some information about $\mathrm{NO}_{2}$ distributions may be obtained at a higher resolution than the individual pixel sizes. In Fig. 10, we compute the maximum daily NAH 

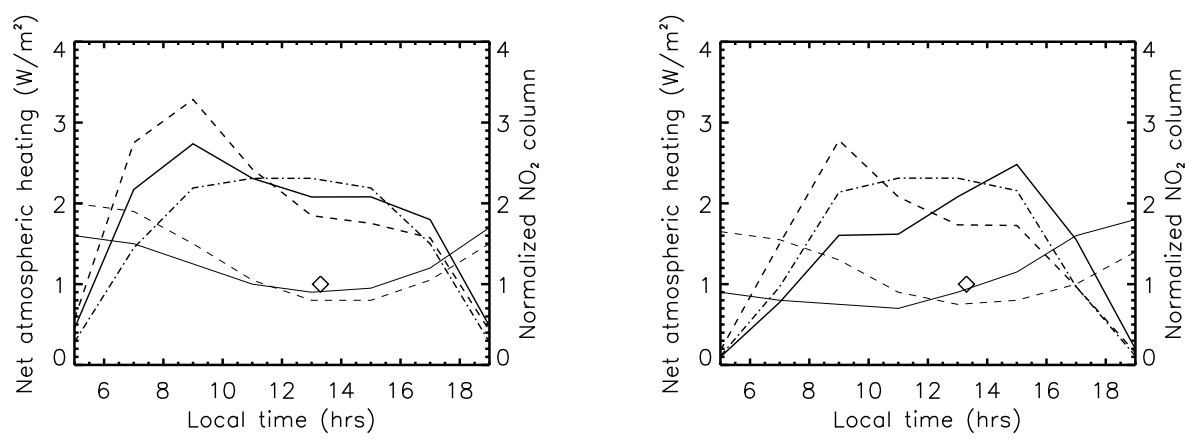

Fig. 9. Diurnal variations in tropospheric $\mathrm{NO}_{2}$ columns (thin lines) and $\mathrm{NAH}$ (thick lines) for the Northeastern US (left) and African regions (right). Diamonds: OMI-derived $\mathrm{NO}_{2}$ column; solid lines: correspond to simulated diurnal variations in $\mathrm{NO}_{\mathrm{x}}$ emissions (see text for details); dashed lines: correspond to constant $\mathrm{NO}_{\mathrm{x}}$ emissions; dot-dash line: $\mathrm{NAH}$ computed for a constant $\mathrm{NO}_{2}$ column corresponding to the OMI derived value.
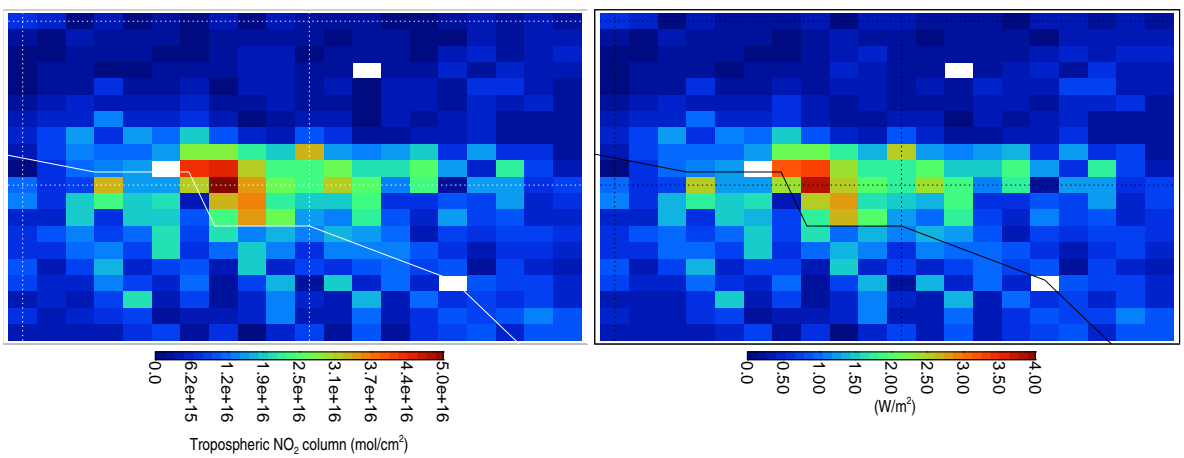

Fig. 10. Annual average $\mathrm{NO}_{2}$ columns (left) and corresponding maximum daily $\mathrm{NAH}$ for 01 July (right) over Los Angeles computed with a $0.1^{\circ} \times 0.1^{\circ}$ grid.

as in Fig. 8, but using $\mathrm{NO}_{2}$ columns gridded to $0.1^{\circ} \times 0.1^{\circ}$ resolution for a region encompassing Los Angeles. In order to maximize the coverage, we averaged all data from 1 January 2005-31 December 2007 and included cloud fractions up to $100 \%$. At this resolution, instantaneous NAHs are approximately a factor of 2 higher than at $1^{\circ} \times 1^{\circ}$ resolution and the sub-grid variability is significant.

\section{Discussion and conclusions}

We showed that absorption by $\mathrm{NO}_{2}$ can be accurately accounted for in standard radiative transfer algorithms using parametrized band-averaged absorption coefficients. Our sensitivity studies showed that $\mathrm{NO}_{2}$ net atmospheric heating in cloudy conditions strongly depends upon the vertical distributions of both $\mathrm{NO}_{2}$ and cloud optical depth in realistic deep convective clouds. Effects of the vertical distributions of cloud optical depth and $\mathrm{NO}_{2}$ on downwelling radiance were simulated for vertically-inhomogeneous convective clouds observed by CloudSat. The simulations showed the maximum effect of $\mathrm{NO}_{2}$ on downwelling radiance oc- cured when the $\mathrm{NO}_{2}$ was located in the middle part of the cloud where the optical extinction peaked. Note that the net heating dependence on layer height that we computed would be virtually the same for any visible or near-IR absorber.

We computed the global distribution of daily maximum and diurnally-averaged $\mathrm{NO}_{2}$ net heating using cloud, surface, and $\mathrm{NO}_{2}$ information from different sensors in the A-train constellation of satellites and $\mathrm{NO}_{2}$ profiles from the GMI. The globally-averaged NAH values are very low because of a small spatial fraction of polluted areas over the globe. The globally-averaged NAH values are about $0.05 \mathrm{~W} / \mathrm{m}^{2}$ only. The zonal means of NAH for mid-latitudes in the Northern hemisphere are approximately twice higher than the globally-averaged values. While the impact of $\mathrm{NO}_{2}$ on the global radiative forcing is small, locally it can produce instantaneous NAH of $2-4 \mathrm{~W} / \mathrm{m}^{2}$ in heavily polluted regions. Because most tropospheric $\mathrm{NO}_{2}$ in polluted areas resides in the planetary boundary layer (PBL), the NAH values can be associated with the atmosphere within the PBL height. Assuming no temperature adjustment, we can roughly calculate the atmospheric temperature change as $\mathrm{NAH} /\left(c_{p} \rho H\right)$, where $c_{p} \approx 10^{3} \mathrm{~J} / \mathrm{kg} / \mathrm{K}$ is the specific heat capacity of air, 
$\rho=1.29 \mathrm{~kg} / \mathrm{m}^{3}$ is the air density, $H \sim 10^{3} \mathrm{~m}$ is the PBL height. Thus, NAH values of $2-4 \mathrm{~W} / \mathrm{m}^{2}$ correspond to $0.16-0.32$ $\mathrm{K} /$ day. These numbers are significantly lower than the average solar heating rate at the surface (about 1-1.5 K/day at SZA of $45^{\circ}$ ) but not negligible.

We assessed the impact of clouds and found that they reduced the globally-averaged NAH values by $5-6 \%$ only. However, because most of $\mathrm{NO}_{2}$ was contained in the boundary layer in polluted regions, the cloud shielding effect significantly reduced the $\mathrm{NAH}$ due to tropospheric $\mathrm{NO}_{2}$ (up to $50 \%)$.

We also examined the effect of diurnal variations in $\mathrm{NO}_{2}$ emissions and chemistry on NAH and found only a small impact of these on the daily-averaged heating. Daily-averaged NAHs are lower for the constant $\mathrm{NO}_{2}$ amount as compared with the diurnally varying $\mathrm{NO}_{2}$ columns (11-14\% for the urban case and 1-6\% for the biomass burning scenario). These differences are relatively small and represent an upper bound on the error in the computed diurnally-averaged NAH. Additionally, the cloud effect reduces the error for an all-sky monthly mean.

Uncertainties in the NAH are due mostly to the uncertainties in the $\mathrm{NO}_{2}$ satellite observations. For clear skies, $\mathrm{NAH}$ is practically proportional to $\mathrm{NO}_{2}$ amount. We show that the dependence of NAH on the vertical profile of tropospheric $\mathrm{NO}_{2}$ is small and the effect of $\mathrm{NO}_{2}$ diurnal variations on the daily-integrated $\mathrm{NAH}$ is small as well. Thus, the $\mathrm{NO}_{2}$ amount uncertainties directly propagate into NAH and relative error in $\mathrm{NAH}$ is determined by relative error in the $\mathrm{NO}_{2}$ observations. Using the estimates of the $\mathrm{NO}_{2}$ observations given in Sect. 4.2.1, we can state that NAH is underestimated by $20-25 \%$ for clear skies. The error estimate is more complicated for cloudy skies. NAH nonlinearly depends on cloud optical depth, cloud height, $\mathrm{NO}_{2}$ amount, and $\mathrm{NO}_{2}$ vertical distribution. However, since clouds reduce the heating for most of the important areas, the clear sky error can be considered as the upper limit of the NAH uncertainties. Surface albedo significantly affects the $\mathrm{NO}_{2} \mathrm{NAH}$ for clear sky. The $\mathrm{NAH}$ values change by approximately $2.0 \mathrm{~W} / \mathrm{m}^{2}$ in the entire range of albedo changes ( 0.0 to 1.0$)$. However, variations of land surface albedo in most $\mathrm{NO}_{2}$ polluted areas are small during a month (January or July). The upper limit of surface albedo can be estimated as 0.05 . Therefore, the uncertainty in the $\mathrm{NO}_{2} \mathrm{NAH}$ due to error in surface albedo has an upper limit of about $0.1 \mathrm{~W} / \mathrm{m}^{2}$. Of course, the NAH errors will be larger in case of variable snow not accounted for in the climatological surface albedo that was used in the computations.

Our computed NAHs are somewhat lower than peak values reported by Solomon et al. (1999). However, it should be noted that the Solomon et al. (1999) measurements were highly localized in both time and space and were likely influenced by thunderstorms that may have produced smallscale $\mathrm{NO}_{2}$ plumes. For our global calculations, we used monthly-averaged $\mathrm{NO}_{2}$ column amounts in gridboxes of $\sim 100 \mathrm{~km} \times 100 \mathrm{~km}$. Averaging at higher spatial resolutions results in higher peak $\mathrm{NO}_{2}$ column amounts, greater heating, and peak values approaches those estimated by Solomon et al. (1999). Solomon et al. (1999) reported estimated atmospheric heating in the wide range of 5 to $30 \mathrm{~W} / \mathrm{m}^{2}$. They assumed a vertically uniform cloud with different $\mathrm{NO}_{2}$ vertical distributions: uniform $\mathrm{NO}_{2}$ mixing ratio throughout the cloud, distributed within bottom or top $2 \mathrm{~km}$, and $80 \%$ distributed throughout cloud with $20 \%$ above cloud. The broad range of atmospheric heating clearly shows the effect of the $\mathrm{NO}_{2}$ vertical distribution on NAH. Solomon et al. (1999) assumed uniform clouds in the absence of data concerning cloud vertical distribution. Our study highlights the importance of vertical cloud structure; therefore our work can be considered as an extension of Solomon et al. (1999) work. We show that $\mathrm{NAH}$ depends not on $\mathrm{NO}_{2}$ distribution solely but on vertical distribution of the cloud extinction. CloudSat data have also proven that clouds are vertically inhomogeneous for a large fraction of cases. Regarding the importance of cloud height, it should be noted that the above consideration is valid when $\mathrm{NO}_{2}$ is placed within a cloud. When $\mathrm{NO}_{2}$ is entirely below the cloud, which is the case for tropospheric $\mathrm{NO}_{2}$ the cloud height and its vertical distribution is not significant. The tropospheric $\mathrm{NO}_{2} \mathrm{NAH}$ mostly depends on cloud transmittance, i.e. on cloud optical depth. Because we lack information about the vertical profile of $\mathrm{NO}_{2}$ within clouds, it remains an open issue.

The stratospheric $\mathrm{NO}_{2}$ contribution to NAH is fairly low but more evenly distributed over the globe. The globallyaveraged NAH values are less than $0.2 \mathrm{~W} / \mathrm{m}^{2}$. However, our radiative transfer computations show that the instantaneous values of $\mathrm{NAH}$ due to the stratospheric $\mathrm{NO}_{2}$ can be as large as $0.5 \mathrm{~W} / \mathrm{m}^{2}$ for clear sky and $0.9 \mathrm{~W} / \mathrm{m}^{2}$ for bright clouds at SZA of $45^{\circ}$.

The radiative impact of $\mathrm{NO}_{2}$ at the surface is dimming (a reduction in solar radiation). Dimming has been increasing over the last several decades primarily due to aerosol indirect effects (e.g., Stanhill and Cohen, 2001). Various estimates of dimming have been reported, and they vary with location. Stanhill and Cohen (2001) estimate a reduction of $20 \mathrm{~W} / \mathrm{m}^{2}$ during the past 50 years $(2.7 \%$ per decade $)$ while Liepert (2002) reports a decline of $7 \mathrm{~W} / \mathrm{m}^{2}$ or $4 \%$ from 1961 to 1990 . Our calculations of the surface irradiance reduction by $\mathrm{NO}_{2}$ is $\sim 1 \mathrm{~W} / \mathrm{m}^{2}$ in the most polluted areas (Southeast Asia). Therefore, although $\mathrm{NO}_{2}$ may be of importance locally in radiative forcing, the trace gas is not likely contributing significantly to the observed global dimming.

$\mathrm{NO}_{2}$ absorption is currently not included in most general circulation model radiative transfer codes. We have shown that it could be easily incorporated using effective absorption coefficients and distributions derived from satellite data or carried on line. In this way, heating from stratospheric $\mathrm{NO}_{2}$, which is comparable to that from tropospheric $\mathrm{NO}_{2}$ in slightly to moderately polluted conditions, can also be included. 
Acknowledgements. The authors thank the OMI and MODIS science teams for the processing and distribution of data sets used here. We also thank Ronald Cohen, Richard Stolarski, and Arlindo da Silva for helpful comments. This material is based upon work supported by the National Aeronautics and Space Administration under agreement NNG06HX18C issued through the Science Mission Directorate for the Aura Science Team. Lazaros Oreopoulos gratefully acknowledges support for this work by the US Department of Energy, Office of Science, Office of Biological and Environmental Research, Environmental Sciences Division as part of the ARM program under grant DE-FG02-07ER64354.

Edited by: R. Cohen

\section{References}

Bey, I., Jacob, D. J., Yantosca, R. M., Logan, J. A., Field, B. D., Fiore, A. M., Li, Q., Liu, H. Y., Mickley, L. J., and Schultz, M. G.: Global modeling of tropospheric chemistry with assimilated meteorology: Model description and evaluation, J. Geophys. Res., 106, 23073-23095, doi:10.1029/2001JD001480, 2001.

Boersma, K. F., Eskes, H. J., and Brinksma, E. J.: Error analysis for tropospheric $\mathrm{NO}_{2}$ retrievals from space, J. Geophys. Res., 109, D04311, doi:10.1029/2003JD003962, 2004.

Boersma, K. F., Jacob, D. J., Eskes, H. J., Pinder, R. W., Wang, J., and van der A, R. J.: Intercomparison of SCIAMACHY and OMI tropospheric $\mathrm{NO}_{2}$ columns: Observing the diurnal evolution of chemistry and emissions from space, J. Geophys. Res., 113, D16S26, doi:10.1029/2007JD008816, 2008.

Bucsela, E. J., Celarier, E. A., Wenig, M. O., Gleason, J. F., Veefkind, J. P., Boersma, K. F., and Brinksma, E. J.: Algorithm for $\mathrm{NO}_{2}$ vertical column retrieval from the Ozone Monitoring Instrument, IEEE T, Geosci. Remote Sens., 44, 1245-1258, doi:10.1109/TGRS.2005.863715, 2006.

Bucsela, E. J., Perring, A. E., Cohen, R. C., Boersma, K. F., Celarier, E. A., Gleason, J. F., Wenig, M. O., Bertram, T. H., Wooldridge, P. J., Dirksen, R., and Veefkind, J. P.: Comparison of tropospheric $\mathrm{NO}_{2}$ from in situ measurements with near-realtime and standard product data from OMI, J. Geophys. Res., 113, D16S31, doi:10.1029/2007JD008838, 2008.

Cede, A., Herman, J., Richter, A., Krotkov, N., and Burrows, J.: Measurements of nitrogen dioxide total column amounts using a Brewer double spectrophotometer in direct Sun mode, J. Geophys. Res., 113, D05304, doi:10.1029/2005JD006585, 2005.

Celarier, E. A., Brinksma E. J., Gleason J. F., et al..: Validation of Ozone Monitoring Instrument nitrogen dioxide columns, J. Geophys. Res., 113, D15S15, doi:10.1029/2007JD008908, 2008.

Chou, M.-D. and Lee, K.-T.: Parameterizations for the absorption of solar radiation by water vapor and ozone, J. Atmos. Sci., 53, 1203-1208, 1996.

Chou, M.-D. and Suarez, M. J.: A solar radiation parameterization for atmospheric studies, NASA Tech. Memo 104606, Vol. 15, 40 pp., 2002.

Duncan, B. N., Strahan, S. E., Yoshida, Y., Steenrod, S. D., and Livesey, N.: Model study of the cross-tropopause transport of biomass burning pollution, Atmos. Chem. Phys., 7, 3713-3736, 2007, http://www.atmos-chem-phys.net/7/3713/2007/.
Forster, P., Ramaswamy, V., Artaxo, P., et al.: The Fourth Assessment Report of the Intergovernmental Panel on Climate Change, edited by: Solomon, S., Qin, D., Manning, M., et al., Cambridge Univ. Press, Cambridge, 2007.

Hansen, J., Sato, M., Kharecha, P., Russell, G., Lea, D. W., and Siddall, M.: Climate change and trace gases, Philos. T. Roy. Soc. A, 365, 1925-1954, doi:10.1098/rsta.2007.2052, 2007.

Hu, Y. X. and Stamnes, K.: An accurate parameterization of the radiative properties of water clouds, J. Climate, 6, 728-742, 1993.

Jin, Z., Charlock, T., Smith, W., and Rutledge, K.: A parameterization of ocean surface albedo, Geophys. Res. Lett., 31, L22301, doi:10.1029/2004GL021180, 2004.

Joiner, J., Vasilkov, A. P., Flittner, D. E., Gleason, J. F., and Bhartia, P. K.: Retrieval of cloud pressure and oceanic chlorophyll content using Raman scattering in GOME ultraviolet spectra, J. Geophys. Res., 109, D01109, doi:10.1029/2003JD003698, 2004.

Joiner, J. and Vasilkov, A. P.: First results from the OMI Rotational Raman Scattering Cloud Pressure Algorithm, IEEE T. Geosci. Remote, 44, 1272-1282, 2006.

Joiner, J., Schoeberl, M. R., Vasilkov, A. P., Oreopoulos, L., Platnick, S., Livesey, N. J., and Levelt, P. F.: Accurate satellitederived estimates of the tropospheric ozone impact on the global radiation budget, Atmos. Chem. Phys. Discuss., 9, 5505-5547, 2009, http://www.atmos-chem-phys-discuss.net/9/5505/2009/.

Levelt, P. F., van der Oord, G. H. J., Dobber, M. R., et al.: The Ozone Monitoring Instrument, IEEE T. Geosci. Remote, 44, 1093-1101, 2006.

Liepert, B. G.: Observed reductions of surface solar radiation at sites in the United States and worldwide from 1961 to 1990, Geophys. Res. Lett., 29, 1421, doi:10.1029/2002GL014910, 2002.

Lucht, W., Schaaf, C. B., and Strahler, A. H.: An Algorithm for the retrieval of albedo from space using semiempirical BRDF models, IEEE T. Geosci. Remote, 38, 977-998, 2000.

Platnick, S., King, M. D., Ackerman, S. A., Menzel, W. P., Baum, B. A., Riédi, J. C., and Frey, R. A.: The MODIS cloud products: algorithms and examples from Terra, IEEE T. Geosci. Remote, 41, 459-473, 2003.

Richter, A., Burrows, J. P., Nuss, H., Granier, C., and Niemeier, U.: Increase in tropospheric nitrogen dioxide over China observed from space, Nature, 437, 129-132, doi:10.1038/nature04092, 2005.

Rienecker, M. M., Suarez M. J., Todling R., et al.: The GEOS-5 data assimilation system - Documentation of versions 5.0.1, 5.1.0, and 5.2.0. NASA Tech. Memo. 2007-104606, vol. 27, edited by: Suarez, M. J., 2007.

Sneep, M., De Haan, J., Stammes, P., Wang, P., Vanbauce, C., Joiner, J., Vasilkov, A. P., and Levelt, P. F.: Three way comparison between OMI/Aura and POLDER/PARASOL cloud pressure products, J. Geophys. Res., 113, D15S23, doi:10.1029/2007JD008694, 2008.

Solomon, S., Portmann, R. W., Sanders, R. W., and Daniels, J. S.: On the role of nitrogen dioxide in the absorption of solar radiation, J. Geophys. Res., 104(D10), 12047-12058, 1999.

Spurr, R. J. D., de Haan, J., van Oss, R., and Vasilkov, A. P.: Discrete ordinate radiative transfer in a stratified medium with first order rotational Raman scattering, J. Quant. Spectrosc. Ras., 109(3), 404-425, 2008.

Stanhill, G. and Cohen, S.: Global dimming: a review of the evidence for a widespread and significant reduction in global radia- 
tion with discussion of its probable causes and possible agricultural consequences, Agr. For. Meteorol., 107, 255-278, 2001.

Stephens, G. L., Vane, D. G., Boain, R. J., et al.: The CloudSat mission and the A-Train: A new dimension of space-based observations of clouds and precipitation, B. Am. Meteorol. Soc., 83, 1771-1790, 2002.

Stephens, G. L., Vane, D. G., Tanelli, S., et al.: CloudSat mission: Performance and early science after the first year of operations, J. Geophys. Res., 113, D00A18, doi:10.1029/2008JD009982, 2008.

Thornton, J. A., Wooldridge, P. J., and Cohen, R. C.: Atmospheric $\mathrm{NO}_{2}$ : In situ laser-induced fluorescence detection at parts per trillion mixing ratios. Anal. Chem, 72, 528-539, 2000.

Tsay, S. C., Stamnes, K., and Jayaweera, K.: Radiative energy balance in the cloudy and hazy Arctic, J. Atmos. Sci., 46, 10021018, 1989.

Vandaele, A. C., Hermans, C., Simon, P. C., Carleer, M., Colin, R., Fally, S., McCrienne, M. F., Jenouvrier, A., and Coquart, B.: Measurements of the $\mathrm{NO}_{2}$ absorption cross-section from $42000 \mathrm{~cm}^{-1}$ to $10000 \mathrm{~cm}^{-1}(238-1000 \mathrm{~nm})$ at $220 \mathrm{~K}$ and $294 \mathrm{~K}$, J. Quant. Spectrosc. Ra., 59, 171-184, 1998.

van der A, R. J., Peters, D. H. M. U., Eskes, H. J., Boersma, K. F., Van Roozendael, M., De Smedt, I., and Kelder, H. M.: Detection of the trend and seasonal variation in tropospheric $\mathrm{NO}_{2}$ over China, J. Geophys. Res., 111, D12317, doi:10.1029/2005JD006594, 2006. van $\operatorname{der}$ A, R. J., Eskes, H. J., Boersma, K. F., van Noije, T. P. C., Van Roozendael, M., De Smedt, I., Peters, D. H. M. U., and Meijer, E. W.: Trends, seasonal variability and dominant $\mathrm{NO}_{\mathrm{x}}$ sources derived from a ten year record of $\mathrm{NO}_{2}$ measured from space, J. Geophys. Res., 113, D04302, doi:10.1029/2007JD009021, 2008.

Vasilkov, A. P., Joiner, J., Spurr, R., Bhartia, P. K., Levelt, P. F., and Stephens, G.: Evaluation of the OMI cloud pressures derived from rotational Raman scattering by comparisons with other satellite data and radiative transfer simulations, J. Geophys. Res., 113, D15S19, doi:10.1029/2007JD008689, 2008.

Wenig, M. O., Cede, A. M., Bucsela, E. J., Celarier, E. A., Boersma, K. F., Veefkind, J. P., Brinksma, E. J., Gleason, J. F., and Herman, J. R.: Validation of OMI tropospheric $\mathrm{NO}_{2}$ column densities using direct-Sun mode Brewer measurements at NASA Goddard Space Flight Center, J. Geophys. Res., 113, D16S45, doi:10.1029/2007JD008988, 2008.

Yang, P., Liou, K.-N., Wyser, K., and Mitchell, D.: Parameterization of the scattering and absorption properties of individual ice crystals, J. Geophys. Res., 105, 4699-4718, 2000.

Ziemke, J. R., Joiner, J., Chandra, S., Bhartia, P. K., Vasilkov, A., Haffner, D. P., Yang, K., Schoeberl, M. R., Froidevaux, L., and Levelt, P. F.: Ozone mixing ratios inside tropical deep convective clouds from OMI satellite measurements, Atmos. Chem. Phys., 9, 573-583, 2009, http://www.atmos-chem-phys.net/9/ 573/2009/. 